\title{
Professor Motivation in Albanian Public Universities: The Case of "Aleksandër Xhuvani" University, Elbasan
}

\author{
Phd Nada Krypa (Tapija) \\ Economic Faculty “A.Xhuvani”University, Elbasan \\ Email:nadakrypa@uniel.edu.al
}

\section{Doi:10.5901/jesr.2014.v4n2p454}

\section{Abstract}

\begin{abstract}
The public universities' professors are the main source of the professional knowledge and skills of all students that attend public education system, Workplace motivation of the Albanian public university system is examined in this paper. Public universities' professors are numerous in size and are considered as a highly professional group; therefore their impact is crucial for accomplishing the demanding goals of Albanian high education system. The main objectives of this research are: (1) to investigate the most relevant dimensions of the workplace motivation in Albanian public universities, and (2) to identify the most prevalent motivation areas that necessitate improvement for enhancing public universities' professors performance. Workplace motivation based data were collected by both primary and secondary research. Professors from the public university of Elbasan were surveyed and further public universities workplace motivation documents and literature have been considered for the purpose of this topic. Through the analysis of the professors motivation in Albanian public universities are identified the main strengths and weaknesses of workplace motivation in high education institutions. In accordance with the contemporary theories of motivation, suggestions are provided for improving the effectiveness and performance of the Albanian public universities' professors.
\end{abstract}

\section{Introduction}

University's professors are beyond doubt one of the most meaningful professional group in Albania. Professor's performance is vital for an improved education and for the future of a country mainly because their capability and performance are the educational basis of the knowledge and competencies that students need for entering the labour market. The purpose of this study was to describe and analyze the motivation dimension of professors in the public university of Elbasan. Motivation is crucial to professors' performance; therefore the motivation component can be wisely used for encouraging commitment towards university's objectives. According to Wortman et al. (Muller, 2010, p. 1) motivation is a driving force "that gives impetus to our behaviour by arousing, sustaining and directing it toward the attainment of goals". Therefore, motivation is the process or mechanism that causes an individual to put efforts and sustain the desired work performance for achieving personal or organizational goals. Professors' motivation of the public university of Elbasan is examined referring to the contemporary theories of motivation which represent the current thinking in workplace motivation.

Contemporary theories are considered to represent the most updated explanations regarding workplace and employee motivation. According to the cognitive theory, motivation is based in two systems: intrinsic and extrinsic motivators. Intrinsic motivators consist on responsibility, recognition, and employee development and growth. Extrinsic motivators consist on payoffs, verbal rewarding, and promotion. Whereas, Goal-Setting Theory implies that motivation and goal setting are interrelated, it supports the idea that motivation and work performance are directly influenced by clear, smart, and challenging goals. In addition, Self - Efficacy Theory considers a person's confidence and capability to perform or accomplish a task. The higher the self-efficacy of an individual the more motivated the person will be for achieving goals. Equity Theory is based on the premise of balance. In simple words, a person's motivation is interrelated with his perceptions about fairness, justice, and equity applied by his superiors. One other theory, one of the most widely applied is the Expectancy Theory. According to Victor Vroom, the probability for one person to act in a specific way depends on the strength of the expectation that this act will drive to the achievement of a desirable outcome. Thus, employees' work and efforts recognition is imperative for enhancing their motivation. Hereupon, through the analysis of motivation variables in the public university this paper will provide insights on how much motivated are the public university professors, as also the most prevalent areas where improvements are needed for increasing professors' motivation. (Robbins and Judge 2009). 


\section{a. Methodology}

In this research the methodology that was used to examine professor motivation in the public university of Elbasan consists on questionnaire. The questionnaire is designed referring to the contemporary theories of motivation. Hence, the research questions reflect the main issues of the motivation in the public university in order to gain proper insights of the workplace motivation. This questionnaire was designed in that manner to provide the necessary quantitative data to calculate the participants' opinions statistically. The number of full time professors in the "A.Xhuvani" University is 219 professors. The questionnaire was sent to 200 professors, a sample size of 135 professors, teaching in the public university "A.Xhuvani in Elbasan, participated in this research, providing a response rate of $75 \%$ percent.

\section{Results}

University 'A.Xhuvani' is an important institution of scientific education in Albania, one of the most prominent universities in the country for the preparation of teachers, specialists and young researchers. The story for nearly four decades has seen significant achievements in many areas of the learning process and research. Before representing the motivation based results of this, it is important to report some important demographic data.

\section{a. Demographics}

Referring to the demographic characteristics of age, displayed in Table 1, it is noticed that out of the total number of the sample, $54.1 \%$ of the respondents of this study are female and $45.9 \%$ are male. In fact this is not surprising , but rather a real reflection of professors' gender composition of the overall educational sector of Albania, where the female presence in education is dominant.

Table 1: Respondents Gender

\begin{tabular}{lcc}
\hline Gender & Number & $\%$ \\
\hline Male & 62 & 45.9 \\
Female & 73 & 54.1 \\
Total & 135 & 100 \\
\hline
\end{tabular}

Regarding the demographic characteristic of age presented in Table 2, results denoted that the prevalent age - group of this study respondents is the one consisting in the age - group of 31 - 39 years old, who made $45.2 \%$ of the entire representative sample. While the number of teachers respondents who were between 40-49 years old was the second interval. These demographic asspects of this sample's age relate to the fact that teaching in the university requires a high degree of abilities and education experience.

Table 2: Professors Age

\begin{tabular}{lcc}
\hline Age & $\mathrm{Nr}$ & $\%$ \\
\hline $\mathbf{2 2 - 3 0}$ & 32 & 23.7 \\
$\mathbf{3 1 - 3 9}$ & 61 & 45.2 \\
$\mathbf{4 0 - 4 9}$ & 42 & 31.1 \\
$>\mathbf{5 0}$ & 32 & 23.7 \\
Total & 135 & 100 \\
\hline
\end{tabular}

Another important demographic facet is professors' marital status, Table 3. Data show that $65.9 \%$ of the study's participants are married. This evidence can be supported by the fact that $90.7 \%$ of the respondents are 31 and above years old, meanwhile Albanian social culture dictates, up to a point, the marriage of people who are above 30 years old. As for the others marital status options the evidences show that the percentage of respondents who were single was $23.7 \%$. While, the percentage $\mathrm{i}$ of the participants who were cohabiting, divorced or widowed was at low levels, comprising almost $11 \%$ of the total sample. 
Table 3: Marital Status

\begin{tabular}{lcc}
\hline Marital status & $\mathrm{Nr}$ & $\%$ \\
\hline Single & 32 & 23.7 \\
Co-habiting & 4 & 3.0 \\
Married & 89 & 65.9 \\
Divorced & 8 & 5.9 \\
Widowed & 2 & 1.5 \\
Total & 135 & 100 \\
\hline
\end{tabular}

Professors' parenthood results shown in Table 4, indicates that $75.6 \%$ of the professors were parents. Being a parent or not, it is an important variable that both impacts and constrains motivation and performance. Professors who are parents, tend to be more motivated and responsible for their educating job, mainly because they want to maintain their incomes for their family.

Table 4: Parenthood

\begin{tabular}{ccc}
\hline Children & $\mathrm{Nr}$ & $\%$ \\
\hline Yes & 102 & 75.6 \\
No & 33 & 24.4 \\
& 135 & 100 \\
\hline
\end{tabular}

As for the educational level' of the professors sample, displayed in Table 5, it is pointed out that $68.1 \%$ had a master degree. While, it is pointed that $31.9 \%$ of participants had a doctorate degree. This evidence might be rationalized that individuals with a doctorate degree most of the professors tend to have a PhD degree after starting teaching in university in order to have a more clear perspective of their specialization area. Moreover, the persuasion of doctorate degree is reflected in the motivation for benefiting both promotion opportunities and increased salary.

Table 5: Education

\begin{tabular}{lcc}
\hline Highest degree earned & $\mathrm{Nr}$ & $\%$ \\
\hline Master & 92 & 68.1 \\
Doctorate & 43 & 31.9 \\
Total & 135 & 100 \\
\hline
\end{tabular}

Another important facet that needs to be noticed is the number of courses professors teach in university. The results displayed in Table 6 indicated that $18.5 \%$ of the respondent professors teach only one course per year and $54.8 \%$ of them teach two courses per year. While, $17.8 \%$ of the respondents teach three courses and only $8.9 \%$ teach four courses per year. University education provides focused and critical knowledge through their courses to the students, as such professors should have the appropriate knowledge background and specialized competencies for teaching in university.

Table 6: Number of Courses

\begin{tabular}{ccc}
\hline Number of courses & $\mathrm{Nr}$ & $\%$ \\
\hline 1 & 25 & 18.5 \\
2 & 74 & 54.8 \\
3 & 24 & 17.8 \\
4 & 12 & 8.9 \\
Other & 0 & 0 \\
Total & 135 & 100 \\
\hline
\end{tabular}

And last but not least important, teaching experience is also investigated in this study. Data displayed in Table 7 , revealed that only $18.5 \%$ of the respondents had $0-2$ years of teaching experience and $28.1 \%$ of the teachers had $3-7$ years of experience, while $53.4 \%$ of the participants in this study had $8-23$ and above years of teaching experience. 
These results are very good regarding the purpose of this study, because information gathered from more 'mature' professors provide deeper insights into motivation dimension. This is mainly because larger experience in teaching provides more reliable knowledge to individuals regarding the workplace environment, their self-capabilities, and helps for professionally growing.

Table 7: Number of years teaching

\begin{tabular}{ccc}
\hline Years teaching & $\mathrm{Nr}$ & $\%$ \\
\hline $0-2$ & 25 & 18.5 \\
$3-7$ & 38 & 28.1 \\
$8-12$ & 48 & 35.6 \\
$13-17$ & 12 & 8.9 \\
$18-22$ & 7 & 5.2 \\
$>23$ & 5 & 3.7 \\
Total & 135 & 100 \\
\hline
\end{tabular}

\section{b. Motivational Variable of Objective Specificity}

Regarding the motivation-based questions respondents were asked to identify which professors' objectives are clearly explained and specified to them from university authorities. The responses are summarized in Table 8.

Table 8: Explained and specified objectives

\begin{tabular}{|l|c|}
\hline Professors' Objectives Specified by University Authorities & $\%$ \\
\hline 1. The positive development of the professor - student relationship & 90 \\
\hline 2. Systematic daily preparation of the classes with efficacy and competence & 88 \\
\hline 3. Collaborating with colleagues, students and others for the development of effective teaching practices & 73 \\
\hline $\begin{array}{l}\text { 4. Applying various teaching methods appropriate to enhance the professional knowledge of the students with different } \\
\text { capacity levels }\end{array}$ & 89 \\
\hline $\begin{array}{l}\text { 5. Personal professional development through self - qualification and advanced qualification agencies } \\
\text { 6. Being competent in the respective courses and in the teaching methods }\end{array}$ & 66 \\
\hline $\begin{array}{l}\text { 7. Using the adequate techniques of students' achievement assessment for motivating them to strive for higher - level } \\
\text { learning objectives }\end{array}$ & 75 \\
\hline
\end{tabular}

From the results it is demonstrated that teacher's objectives such as: "Being competent in the respective course and in the teaching methods" specified by $99 \%$ of the respondents, "The positive development of the professor-student relationship", which was assumed to be well - clarified $90 \%$ of the respondent professor, "Applying various teaching methods appropriate for the enhancement of the professional knowledge of students with different capacity levels" comprising $89 \%$ of the sample, and "Systematic daily preparation of the class with efficacy and competence" specified as well for $88 \%$ of the participants it can be assumed that professors' objectives are well explained and clearly specified. Thereupon, professors are properly informed about what is required by them. It is easily observable that these objectives that are most rated from respondent professors reveal the objectives that tend to increase student knowledge and skills. Besides, other important objectives are also required form professor (gathered through open-ended questions) such as: educational level, professional preparation, students' final results. Meanwhile the teachers, clearly specified objectives rated at least

\section{c. Motivational Variable of Training}

Training variable data in Table 9 displayed that $0 \%$ of the respondents stated that training is "always" provided, while $4.4 \%$ of the survey's participators stated "often", $20.7 \%$ of them replied "rare" and $74.8 \%$ claimed that training is "never" secured or undertaken. These, training - based data presented here, indicate that training is not considered by university authorities as an important factor for enhancing motivation and teachin performance. 
Table 9: Training

\begin{tabular}{lcc}
\hline & Have there been provided training, courses, seminars \\
\hline & $\mathrm{Nr}$ & $\%$ \\
Yes, always & 0 & 0 \\
Often & 6 & 4.4 \\
Rare & 28 & 20.7 \\
Never & 101 & 74.8 \\
Other & 0 & 0.0 \\
$\quad$ Total & 135 & 100 \\
\hline
\end{tabular}

Self - efficacy theory, stresses that self - efficacy increase individual's confidence for being able to succeed in a task. And one of the most efficient mechanisms that is used for increasing the employee's self - confidence is training (Robbins and Judge, 2009).

\section{d. Motivational Variable of Intrinsic Rewards}

Referring again to Robbins and Judge (2009), Cognitive theory argues that intrinsic motivators are linked with internal locus of control, whick makes individuals to believe they have control of their own behaviour. Meanwhile, extrinsic motivators are linked with external locus of control, meaning individuals believe that others or external environment impacts their behaviour. Due to this fact, it is very important that professors should be motivated only by intrinsic motivators for improving their teaching performance. Table 10 represents the data gathered regarding intrinsic motivation dimension of the university. Professors through the questionnaire were asked to give their opinion for five different variables. The variable 1,"Teaching is a challenging work", was pointed out by $97 \%$ of professors, including those who "strongly agreed" and "agreed". None of the respondents did not "disagree" or "strongly disagree" and only $4 \%$ were neutral with that statement. This in fact reflects the reality of Albanian educational system which is continuously changing; therefore changes in curriculum and teaching programs are constant.

Regarding, variable 2 of intrinsic motivation "I spend some of my free time by reading professional books and articles, attending workshop and meeting for being improved professionally", 82\% of participants strongly agreed and 675 agreed, 10\% were neutral and again none of them disagreed. Courses in public universities are highly specialized consisting in concepts and topics that require periodic updates.

Table 10: Intrinsic motivation

The extent to which you agree or disagree with the statement

\section{Teaching is a challenging work}

2. I spend some of my free time by reading professional books and articles, attending workshop and meeting for being improved professionally

3. My students think l'm a good professor

4. The average number of students that show interest and pay attention during the classes is relatively good

5. The education system of public university gives me opportunity to grow and develop professionally

$\begin{array}{ccccc}\text { SA } & \text { A } & \text { N } & \text { SD } & \text { D } \\ 19 \% & 78 \% & 4 \% & & \\ 82 \% & 67 \% & 10 \% & & \end{array}$

$15 \% \quad 46 \% \quad 21 \% \quad 10 \% \quad 1 \%$ $10 \% \quad 90 \%$

$2 \% \quad 1 \% \quad 1 \% \quad 28 \% \quad 22 \%$

Intrinsic motivator variable 3, "My students think I'm a good teacher", results are spread among all the optional answers, and where "agree" dominates with $46 \%$. Recognition as an reward is a very important intrinsic motivators. Hence, we can suggest that respondent professors are moderately motivated referring to recognition motivation dimension. "The average number of students per class that show interest and pay attention during the classes is relatively good" statement revealed that respondents were indifferent $90 \%$ were neutral and only $10 \%$ agreed. This variable means that students' interest and attention are at medium levels indicating that professors are not highly stimulated to be more committed and internally motivated during teaching. And last intrinsic motivator consists in the statement "The education system of public university gives me opportunity to grow and develop professionally." revealed that $50 \%$ of the respondents disagreed, while only $3 \%$ of the sample agreed. The significant size of disagreement implies that public 
university system does not ensures opportunities for development and growth, consequently decreasing professors motivation for contributing and performing better.

\section{Conclusions and Recommendations}

This project is an analysis of the main dimensions of the professor motivation in the Albanian public university of Elbasan. The research strategy of this study was based in the contemporary theories of motivation.

With regard to the specificity dimension of the teacher's objectives, it was revealed that not all of the teacher's objectives were well - specified and explained to the professors of the public university of Elbasan.

Training is not provided consistently

As the intrinsic rewards are recognized as crucial rewards that cause high employee motivation, it was revealed that Albanian are moderately intrinsically motivated.

to improve their job performance level and to accomplish all of their teacher's objectives successfully there are necessitated the following motivation - based intervention such as: well - specifying and clarifying all of the respective teacher's objectives; setting teacher's objectives that are realistic and reachable

securing pertinent teacher training whenever the change affects the teaching activities and/or teacher's objectives; with the teacher training content that enable them to approach to their teacher's objectives smoothly; increasing the incidence of ensuring 'training for specific courses', inasmuch as it is the most effective method of teacher training as well as increasingly using the new methods of teacher training such as 'training on distance' and 'mixed training'

Provide opportunities for development

\section{References}

Champoux, J. (2011). Organizational Behavior: Integrating Individuals, Groups, and Organizations (4th ed.). New York: Routlegde. Muller Ch. (2012) Employee motivation and incentives at Apple:Essay Grin Publish \& Find Knowlege Northouse, P. G. (2010). Leadership: Theory and Practice (5th ed.). California: Sage Publication, Inc. Phillips, J., \& Gully, S. M. (2011). Organizational Behavior: Tools for Success. Mason: Cengage Learning. Robbins, P. S., \& Judge, A. T. (2009). Organizational Behaviour (13 th ed.). New Jersey: Prentice-Hall Inc. 